\title{
12: Health security among internally displaced and vulnerable populations in eastern Burma
}

\author{
Mahn Mahn, Katherine C. Teela, Catherine I. Lee and Cara \\ O'Connor
}

\section{Introduction}

Since 1962, Burma has been ruled by a military junta, currently known as the State Peace and Development Council (SPDC), which has brutally suppressed the population, particularly ethnic minority groups. Burma is one of the most ethnically and linguistically diverse countries in the world and ethnic minorities make up a large part of its population, inhabiting approximately half of the land area of the country, especially along the country's mountainous border frontiers. Since 2005, the military regime has greatly intensified its violent campaigns against a number of groups including the Karen, Karenni, Mon and Shan communities in eastern Burma, while maintaining strict rule in central regions as well.

More than 50 years of civil war in Burma have displaced hundreds of thousands of ethnic people. They have fled their homes, hidden for safety and/or faced forced relocation. Compounding their loss of home and security, conflict and human rights violations have stolen their basic human right to health - with those living along the border and in the remote interior of Burma most severely affected. The military junta has consistently blocked efforts by community-based and international organisations to deliver humanitarian aid to these restricted border regions. Alternative approaches to the provision of basic and essential public health programs in these areas that utilise the existing ethnic health organisations are urgently needed.

\section{The current security situation in eastern Burma}

In addition to continuing human rights violations by the SPDC during the construction of roads and other development projects - in particular, the widespread use of forced labour - pervasive offensives continue to be waged in the areas in which cross-border health organisations provide services. Both forms of military presence are known to increase human rights violations (Burma Human Rights Yearbook 2006). As these rights violations and fighting continue, 
so does the displacement of villagers as families flee to the jungle and yet-to-be attacked villages.

One example of a military-led development project that is increasing rights violations and having direct implications on access to health care is the continued construction of a road meant to link SPDC camps in the north and south of Toungoo District in northern Karen State. The construction of this road means that increased numbers of military personnel occupy the area and whole villages have been forced to move. Villagers are forced to work on the construction of the road and many flee to avoid direct attack and conscription at the hands of the SPDC. In addition, the new road creates a formidable barrier that blocks attempts by villagers to escape attacks. It also puts those who do attempt to cross the road at increased risk of attack and landmine injury as it is common practice for the Tatmadaw to shoot on sight as well as to place landmines on either side of the road.

The risk is the same for health workers. This is just one of the many examples of how development and rights violations by the SPDC decrease villagers' access to health by cordoning off the path by which they can access health facilities and blockading the way by which mobile medical units can reach those in hiding. This road, like others constructed by the junta, will inevitably lead to an increased military presence and attempts to control the area, as well as efforts by the Burmese Government to increase access to these ethnic areas in order to create more projects such as the development of goldmining operations and access for the construction of dams - all of which, as has been shown by several groups, creates and increases the number of human rights violations perpetrated by the Burmese armed forces (Burma Human Rights Yearbook 2006; Karen Human Rights Group 2006). In turn, as shown in Chronic Emergency (2006), associations exist between these rights violations and health outcomes. Not only are villagers faced with direct threats from rights violations, they face detrimental outcomes to household-level health such as high malnutrition rates among children and high malaria prevalence.

In addition to militarisation for the purpose of development projects, there are continuing attempts by the SPDC and some cease-fire groups to control a greater amount of territory. This leads inevitably to an increase in fighting between armed combatants. The SPDC continues to commit human rights violations against civilians as a strategy to weaken these resistance groups. In recent years, the frequency of these attacks has increased. Since February 2006, 370 people have been killed and more than 30000 villagers have been displaced as a direct result of attacks from the Burmese army (Chronic Emergency 2006). The Burmese army has increased its presence in almost all border areas, typically in the post-rainy season military offensives, which have increased in frequency and intensity in recent years. 
In addition, the military presence in the border regions, including the area controlled by Burma's main cease-fire group, the Kachin Independence Organisation (KIO), is increasing (see Naing 2007). In part, this is due to normal seasonal advances by the Burmese military, but it is also linked to fallout from the brutal crackdown after the 'Saffron Revolution' protests that occurred in September 2007. For the KIO area, the increase in military tensions was brought on by its refusal to issue a statement in opposition to that released by UN Special Envoy for Burma, Ibrahim Gambari, on behalf of detained democracy leader Aung San Suu Kyi. This is not the only area to witness an increase in military presence since the protests and across the country tensions have risen. In all areas where the military presence and activity are increasing, villagers will be the ones to bear the brunt of human rights violations, forced labour, active fighting, the placement of landmines and the levying of taxes.

These factors, the lack of adequate and appropriate community and facility-based health care and the results shown in Chronic Emergency (2006) clearly indicate the need for interventions for these vulnerable populations in internally displaced person (IDP) communities. The action, however, must come from border-based programs, developed and implemented by health workers and individuals from the communities in which the programs take place. These organisations have a unique knowledge of the situation and thus access to IDP populations not otherwise accessed by organisations, particularly international non-governmental organisations (NGOs). The need for border-based healthcare programs is apparent and utilising the existing infrastructure of ethnic health organisations is the only way these vulnerable populations will receive basic primary health care and public health interventions. In the remainder of this chapter, we document precisely the forms of cross-border health intervention that can reach and sustain the vulnerable and internally displaced populations living in Burma's eastern conflict zones.

\section{The health status of internally displaced persons}

According to official figures, Burma's health indicators are currently among the worst in the region. Information collected by the Back Pack Health Worker Team (BPHWT) from the eastern frontiers of the country, where communities have faced decades of civil war and widespread human rights abuses, indicates an even greater public health catastrophe in areas where official figures are not collected.

A survey conducted in 2004 by the BPHWT showed malaria to be the most common cause of death, with more than 12 per cent of the population at any given time infected with Plasmodium falciparum, the most dangerous form of malaria (Fox and Kumchum 1996). Malnutrition is unacceptably common, with more than 15 per cent of children at any time showing evidence of at least mild malnutrition - rates far higher than their counterparts who have fled to refugee 
camps in Thailand. The World Food Program, which includes more than mild malnutrition in its calculations, estimates that 32 per cent of children under five years of age in Burma are malnourished.

Human rights violations are very common in this population. In the year before the survey was conducted, almost one-third of households had suffered from forced labour, almost 10 per cent experienced forced displacement at least once and one-quarter reported that their food had been confiscated or destroyed. Approximately one in 50 households had suffered violence at the hands of soldiers and one in 140 households had a member injured by a landmine within the past year alone.

The report, Chronic Emergency, was the first to measure basic public health indicators and to quantify the extent of human rights abuses among IDP communities in the eastern conflict zones of Burma. These results indicated that the poor health status of these communities was intricately and inexorably linked to the human rights context in which health outcomes were observed. Without addressing the widespread human rights abuses and inability to access healthcare services, a long-term, sustainable improvement in the public health of these areas cannot occur.

\section{Border-based health programs}

Life under the junta and the consistent armed conflict that plagues Burma have resulted in the flight of more than one million indigenous Burmese, who have sought asylum in camps across the border, and in 600000 to one million IDPs (Mullaney et al 2008; Skidmore 2003). Health care within Burma is grossly deficient in terms of coverage, utilisation and technical quality (Fox and Kumchum 1996), with the government spending only 2.2 per cent of total gross domestic product (GDP) on health care (Sullivan et al. 2004). In addition, the junta's 'four-cuts' policy - a broad effort to cut off food, funding, information and recruits for opposition groups, mainly in the border regions, through extensive and collective human rights violations such as forced displacement, forced labour and destruction of food supplies - worsens the health of IDPs. This imposed 'burden of ill health' weakens the IDP community and helps the junta keep this population subjugated.

Finding ways to provide health care to IDPs is a particular priority for indigenous and international groups that are consistently restricted by the junta (Beyer et al. 2006; Stover et al. 2007). The withdrawal of the Global Fund to Fight AIDS, Tuberculosis and Malaria from Burma in 2005, because of the increasingly restrictive parameters placed on its work, highlights the need for alternative strategies to reach IDPs in the border regions.

One method of providing health care to IDPs is through border-based work: programs administered and managed from locations in neighbouring countries 
that carry out their activities inside Burma. By basing themselves in neighbouring countries, these organisations are able to support and develop a system of mobile clinics and teams of indigenous mobile medics, who have unique access to the vulnerable populations within Burma. ${ }^{1}$

Cross-border work is becoming increasingly credible as a way to get health care to populations in conflict zones, as illustrated by the increased support from organisations funding border-based work. In addition, the local capacity of border-based health organisations has increased to allow for the receipt of funds to work along Burma's borders with Thailand, India and China and, to a lesser extent, with Bangladesh. Financial support for border-based work, however, is still lacking and deserves more attention and funds, as this is the only way in which these populations can be accessed. Here we will focus on organisations working from Thailand. Below are brief descriptions of a select group of border-based organisations working along the Thai-Burma border, many of which collaborate to develop programs and health policies.

\section{Back Pack Health Worker Team}

In an attempt to address the healthcare crisis in eastern Burma by establishing a consistent primary healthcare provision program for IDPs, medics and leaders from Karen, Karenni and Mon States formed the Back Pack Health Worker Team (BPHWT) on 19 August 1998. The BPHWT aims to equip people with skills and knowledge in order to manage and solve their own health problems, while working towards sustainable development in Burma. All BPHWT activities take place inside Burma, but the organisation's headquarters is in Thailand, where a team of medics, doctors, coordinators and administrators runs the program.

The BPHWT works by sending groups of mobile medics and supervisors, arranged in teams of three to five individuals, into eastern Burma to provide primary healthcare services as well as medical care for injuries (from landmines, gunshot wounds) and reproductive health care (safe births and family planning). As well, the BPHWT coordinates with other networks such as schools and women's groups to disseminate health education to local communities; it provides medical and other necessary supplies for community health workers, organises seminars and workshops to increase the knowledge and skills of health workers and collects and analyses health data.

Each BPHWT team is responsible for a specific catchment area, with an average population of 2000 people. A select group of these medics goes to Thailand to receive biannual training, to restock supplies and return health data from the field before returning to train the rest of the medics in their teams at field sites in IDP areas. In addition, these workers train traditional birth attendants (TBAs), village health volunteers and various other individuals whose work is health related. 
In 2000, the BPHWT launched its TBA program, with a goal of addressing the high maternal and neonatal mortality among IDPs in this conflict zone. In these areas, community-based provision of reproductive health care through highly mobile TBAs enables a degree of access that is not feasible via the more traditional facility-based approaches. The BPHWT provides training, supplies and overall coordination for the TBA program from Thailand.

\section{Mae Tao Clinic}

The Mae Tao Clinic was started in 1989 by Dr Cynthia Maung, a Burmese refugee, in response to the need for healthcare provision for those fleeing to the Thai-Burma border to escape the brutal crackdown in central Burma and offensives by the Burmese military in the border region. The Mae Tao Clinic has grown into a comprehensive healthcare provision centre that includes an inpatient and outpatient department (IPD/OPD), reproductive health (which includes basic emergency obstetric care), a laboratory, prosthetics department and an HIV/AIDS prevention centre (Mae Tao Clinic 2006).

As well as providing services on the Thai side of the border, the Mae Tao Clinic is significantly involved in border-based work. The Mae Tao Clinic supports three clinics inside Burma and serves as a training hub for clinical skills as well as human rights awareness training, computer literacy and community management for medics working on either side of the border.

\section{Burma Medical Association}

The Burma Medical Association (BMA), a health professional-based organisation, was founded in 1991. The association conducts extensive border-based programs in communicable disease control and maternal and child health, as well as focusing on health curriculum development, health policy development, coordination of health worker training and offering technical support to public health programs on the border. The BMA also serves as a networking entity and a communications hub for border-based health work on the Thai-Burma border.

\section{National Health and Education Committee}

The National Health and Education Committee (NHEC) is an ethnic organisation-based entity that focuses on health and education policies/programs for ethnic nationalities and democratic groups. It coordinates health and education departments along the Burmese border and supports local border-based health groups through health policy and system development. The committee also supports ethnic health departments by providing training on various topics.

\section{Ethnic health departments}

Ethnic health departments partner with border-based health organisations by establishing health centres/clinics inside Burma, organising health training 
within Burma, developing health structure and management, recruiting and managing human resources and recognising health-worker status in the field. In addition, the departments manage supplies procurement and develop and maintain distribution to medics and health providers in the field. Ethnic health departments serve as centres of training and information about the health status of populations in their areas and provide valuable contact with the above-mentioned clinics and health centres operating in IDP areas.

An example of an ethnic health department working from the Thai-Burma border is the Karen Department of Health and Welfare (KDHW). The KDHW operates 33 mobile health clinics in Karen State, each of which serves approximately 3500-5000 people (Karen Department of Health 2006). Medics in these clinics, originally trained at the Mae Tao Clinic, can treat malaria, vitamin deficiency, intestinal parasites, landmine injuries and other common illnesses. Management of the mobile health clinics, as well as program design and monitoring/evaluation of other programs, is handled by a team based in Thailand.

\section{Partner organisations}

Several organisations - internationally and within Thailand - support the work of border-based organisations. This support ranges from financial to that of a more technical nature with regard to program design and implementation, as well as monitoring and evaluation. In addition, some groups specifically provide support to develop the capacity of these groups to grow and more effectively address the needs of their communities.

One example of a partnering organisation is the Planet Care/Global Health Access Program (GHAP; <www.ghap.org $>$ ), which has been working with local groups on border-based healthcare programs since 1998. Program staff and volunteers work closely with local groups operating programs in the IDP border areas by providing technical assistance and building local capacity in the area of public health program design, implementation, monitoring and evaluation. The GHAP also assists in the analysis and recording of program outcomes for improvement and advocacy work.

\section{Case study: Border-Based Reproductive Health Coordination Group}

In 2007, reproductive health coordinators from the BMA, the KDHW, the BPHWT, the Mobile Obstetric Maternal (MOM) Health Worker Project, the Karen Women's Organisation and the Mae Tao Clinic, together with members of GHAP, formed the Border-Based Reproductive Health Coordination Group. The group seeks to exchange ideas on reproductive healthcare provision in the conflict zones of eastern Burma. 
In regular meetings, program coordinators discuss recent activities, share challenges and solutions and strategise about expansion and implementation within each organisation's reproductive health program. In this way, the coordination group brings about a better understanding of how collaboration between programs can strengthen the larger IDP community. Supply procurement, logistics, training and other issues are made easier as a result of the partnerships formed among the organisations. Finally, these regular networking meetings build capacity among local project coordinators, empowering them as leaders of their displaced communities.

Many of the organisations in the networking group are operating extensive TBA programs. TBA programs in this region have unique organisational goals and financial/human resources, but they share common goals of improving access to, and the quality of, reproductive healthcare for IDPs, as well as the collection and dissemination of vital maternal and neonatal health data. Because of these common goals, organisations have come together for program development and design on several occasions. One such example was the creation of a unique standardised pictorial TBA data-collection form, which has since improved data sharing and dissemination.

Given the difficulty of coordinating, supplying and training TBAs within conflict zones, it is essential that programs cooperate towards achieving common goals. As the example of the Border-Based Reproductive Health Coordination Group shows, networking and standardisation of data collection and future program design can strengthen border-based TBA programs. The success of this coordination should be a model for the future development of similar networks for other pressing issues such as malaria control and health education.

\section{Case study: health information systems training}

The efficient collection of data and the analysis of information are critical to the success of health organisations. The longstanding civil conflict in eastern Burma has effectively stopped any flow of official health information from the region. The ethnic health organisations serving IDPs in these 'black zones' are therefore the main source of data about health status in the region.

In 2006, an initial needs assessment found that the development of technical skills for data management and the creation of comprehensive border-wide health information systems (HIS) were among the highest priorities for border-based health organisations. The assessment also determined that a standardised data-management curriculum applicable to these groups did not exist. In response, four border-based health organisations - the BMA, the Mae Tao Clinic, the BPHWT and the KDHW-organised intensive HIS training. The specific objectives of the training were: 1) to build the capacity of organisational staff to manage HIS; 2) to standardise data-collection procedures and data management 
between border-based health providers; 3) to establish regular coordination and communication between cross-border health providers regarding HIS; and 4) to use data for targeted program planning and advocacy.

During the initial 10-week training period, 28 trainees from six different border-based health organisations were equipped with the basic skills needed to create data-collection forms, to calculate important indicators of health status, to manage databases and to analyse data for program planning and advocacy. Training was facilitated by a trainer from GHAP and by the Mae Tao Clinic HIS coordinator. Through monthly follow-up meetings, the trainees continue to coordinate their data-collection and reporting efforts, monitor progress on HIS projects, troubleshoot and upgrade their skills.

As a result of the initial training, organisations have updated their program databases, reducing data-entry errors and improving data quality. Some groups are in the process of updating their data-collection forms to more efficiently collect the information they need to calculate health indicators. This increase in local capacity for HIS reduces the need for outside technical advisors and greatly enhances program sustainability and ownership. Moreover, the coordination of data collection and reporting across multiple border-based organisations strengthens their program planning and advocacy abilities and generates new knowledge about the health status of the population in Burma's 'black zones'.

\section{Success of border-based health programs}

\section{Case study: expansion of the BPHWT}

The BPHWT faces a number of challenges in carrying out its work. Security risks and the junta's 'four-cuts' policy restrict travel, which hinders healthcare service provision in the field as well as the attendance of training sessions by BPHWT workers. Data records, training materials and supplies are sometimes lost when workers are forced to flee an attack, or are confiscated by the military. Some health workers have been arrested and even killed. For example:

The SPDC attacked a village in Du Playa when they heard the BP team was treating villagers. The team and villagers fled to the jungle, one of the men taking care of BP security was shot in the shoulder. Later when it was safe to return, they discovered the house they had been treating patients in was burnt to the ground. (BPHWT 2001)

Despite these challenges, however, the BPHWT provides an indispensable service to IDPs in eastern Burma and has continued to grow. Through collaboration and mutual support from other border-based groups, the BPHWT has expanded greatly since 1998. In 1998, there were 32 BPHWTs; in 2007, 76 teams were working in 17 areas. The BPHWT now works in Karen, Karenni, Mon and Shan States in eastern Burma, as well as cooperating in an integrated program in Chin 
State and a pilot program in Arakan (Rakhine) State. The total number of cases treated by BPHWT medics in 2006 was 71789 (BPHWT 2006). The TBA program has grown extensively, from 55 trained TBAs in 2000 to 725 in 17 areas in 2007. An essential part of this program is the repeated follow-up training provided to TBAs trained by the BPHWT. TBAs supported by the BPHWT receive biannual training to improve skills, receive new knowledge regarding health interventions and discuss improvements to the program. This continued support and regular contact with TBAs supports the quality of the program and builds up TBA skills over time (see Table 12.1 on the growth of the BPHWT).

Table 12.1 BPHWT: number of teams and intended target population

\begin{tabular}{|l|l|l|l|}
\hline Year & Number of BPHWT teams & Number of TBAs & Target population of IDPs \\
\hline $\mathbf{1 9 9 8}$ & 32 & - & - \\
\hline $\mathbf{1 9 9 9}$ & - & - & - \\
\hline $\mathbf{2 0 0 0}$ & 56 & 55 & 100000 \\
\hline $\mathbf{2 0 0 1}$ & 60 & 200 & 120000 \\
\hline $\mathbf{2 0 0 2}$ & 70 & 200 & 140000 \\
\hline $\mathbf{2 0 0 3}$ & 70 & 200 & 140000 \\
\hline $\mathbf{2 0 0 4}$ & 70 & 230 & 140000 \\
\hline $\mathbf{2 0 0 5}$ & 70 & 460 & 140000 \\
\hline $\mathbf{2 0 0 6}$ & 76 & 720 & 150000 \\
\hline $\mathbf{2 0 0 7}$ & 76 & 720 & 150000 \\
\hline
\end{tabular}

Sources: BPHWT annual reports and six-monthly reports, 1998-2007.

\section{Case study: KDHW Malaria Control Program}

The KDHW launched a Malaria Control Program (MCP) in 2003. Administered and managed from Thailand, the program consists of a team of medics, the members of which live and work in communities within Burma where they provide care. They return to Thailand every six months for refresher training, to restock supplies and share data. The MCP has grown extensively since 2003, with 50 medics and a network of village health workers providing malaria-control services to 40859 people in 53 areas in Karen State (Table 12.2).

Table 12.2 KDHW MCP program expansion

\begin{tabular}{|l|r|r|r|r|r|}
\hline & \multicolumn{1}{|c|}{2003} & \multicolumn{1}{|c|}{2004} & \multicolumn{1}{|c|}{2005} & \multicolumn{1}{c|}{2006} & \multicolumn{1}{c|}{2007} \\
\hline Areas covered & 4 & 5 & 17 & 36 & 53 \\
\hline Households & 398 & 554 & 2041 & 5800 & 7501 \\
\hline Population & 1868 & 3460 & 9798 & 31646 & 40859 \\
\hline
\end{tabular}

The KDHW MCP conducts malaria-prevention education activities, vector control through insecticide-treated mosquito nets, early diagnosis with Paracheck diagnostic tests and Artesunate combination therapy for treatment. In addition, it includes 'directly observed therapy' for Artesunate combination therapy treatment and biannual population screening and treatment. Finally, MCP medics promote community participation by relying on the volunteer health workers 
that they recruit and train to conduct house visits to monitor mosquito-net use and provide education.

The KDHW MCP has shown enormous success since its inception in 2003. Approximately 90 per cent of people in the target area sleep under insecticide-treated nets every night and 95 per cent of those diagnosed with malaria have completed directly observed therapy. As illustrated in Figure 12.1, the prevalence of Plasmodium falciparum ( $P f)$ malaria has decreased in each target area since inception of the MCP. The program also serves as a platform from which to gather essential data from the target population. For example, between 2002 and 2006, the KDHW MCP network and members of the GHAP conducted an extensive study on the prevalence of $P f$ malaria in Karen State (BPHWT 2006).

\section{Figure 12.1 Pf malaria prevalence by term (KDHW MCP)}

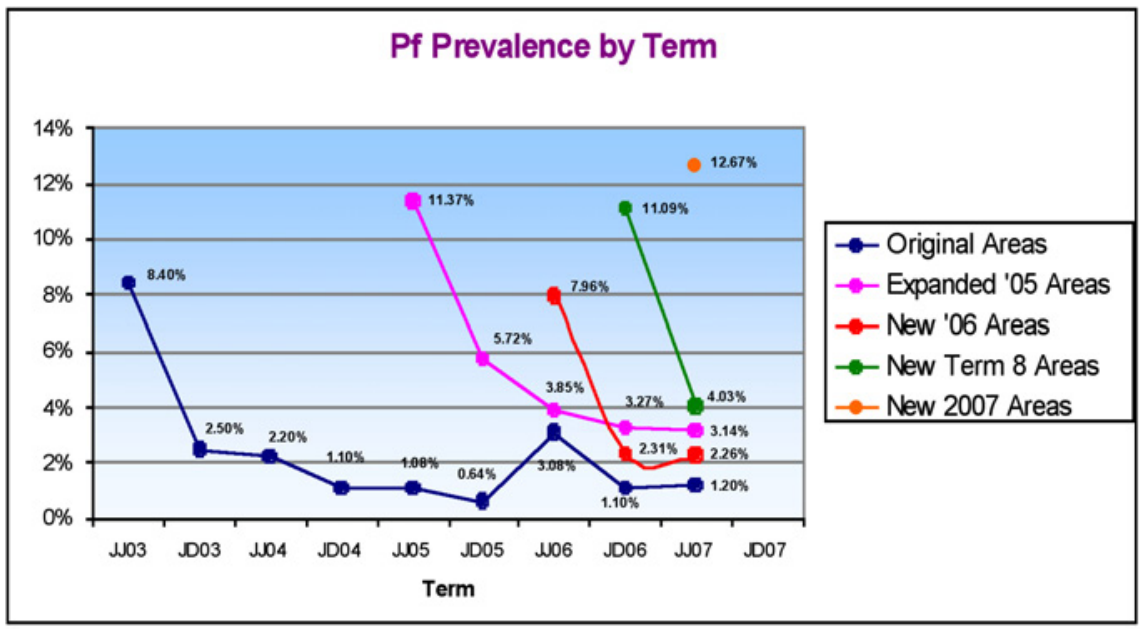

\section{Conclusion}

Continued conflict and consistent human rights violations have increased mortality rates and worsened the health status of IDPs and other vulnerable populations in Burma. Collaboration with and partnerships among border-based health organisations have proved to be viable solutions towards providing primary health care to these vulnerable populations, and should be a focus for the international public health community. Without an end to human rights violations in Burma, however, any improvements in health status are unlikely to be sustained. 


\section{References}

Back Pack Health Worker Team (BPHWT) 2001 Annual Report 2001, Back Pack Health Worker Team, Mae Sot, Thailand.

Back Pack Health Worker Team (BPHWT) 2006 Annual Report 2006, Back Pack Health Worker Team, Mae Sot, Thailand

Backpack Workers Health Team, 2006 Chronic Emergency: Health and Human Rights in Eastern Burma, Open Society Institute, Bangkok Available at: www.geocities.com/maesothtml/bphwt/index.html.

Beyrer C, Suwanvanichkij V, Mullany LC, Richards AK, Franck N, Samuels A, et al. 2006, 'Responding to AIDS, tuberculosis, malaria, and emerging infectious diseases in Burma: dilemmas of policy and practice'. PLoS Medicine Oct;3(10):e393. I

Human Rights Documentation Unit, 2006 Burma Human Rights Yearbook, National Coalition Government of the Union of Burma. Available at: http://www.ncgub.net//BHRY/2006.

Fox, P. G. and Kumchum, S. 1996,'Caring for Myanmar refugees in Thailand', International Nursing Review 43:154-8.

Karen Department of Health and Welfare, 2006, Annual Report 2006, Karen Department of Health and Welfare, Mae Sot, Thailand.

Karen Human Rights Group, 2006(a), Less than Human: Convict Porters in the 2005 - 2006 Northern Karen State Offensive, Mae Sot, Thailand.

Karen Human Rights Group, 2006(b), Toungoo District: The civilian response to human rights violations, Mae Sot, Thailand.

Karen Human Rights Group, 2006 (c), Dignity in the Shadow of Oppression: The abuse and agency of Karen women under militarisation, Mae Sot, Thailand Karen Human Rights Group, 2007 Development by Decree: The politics of poverty and control in Karen State, Mae Sot, Thailand.

Mae Tao Clinic, 2006 Annual Report, Mae Tao Clinic, Mae Sot, Thailand. Available at: www.maetaoclinic.org/publications

Mullany L.C., Lee C.I., Paw P., Shwe Oo E.K., Maung C., Kuiper H., et al. 2008 'The MOM Project: delivering maternal health services among internally displaced populations in eastern Burma', Reproductive Health Matters. May;16(31):44-56.

Skidmore, M. 2003, 'Medical assistance and refugee safety in contemporary conflicts', Lancet, 362(9377):75.

Stover, E; Suwanvanichkij, V; Moss, A. 2007, The gathering storm: infectious diseases and human rights in Burma. 
Sullivan, T. M., Maung, C., Sophia, N. 2004, 'Using Evidence to Improve Reproductive Health Quality along the Thailand-Burma Border', Disasters, 28(3):255-268.

\section{Endnotes}

1 They face a whole new set of issues, however, in terms of procurement and program management; sometimes they have an illegal status; and there are issues relating to security and payments required by local authorities. 